\title{
Safety Evaluation on Building Construction Based on Hopfield Neural Network
}

\author{
Huiqin $\mathrm{GaO}^{1,2, \mathrm{a}}$ \\ ${ }^{1}$ Faculty of Construction Management and Real Estate, Chongqing University, Chongqing,40045, China \\ ${ }^{2}$ School of Management Engineering, Shandong Jianzhu University,Jinan,250101,China \\ agaohuiqinsdjz@163.com
}

\begin{abstract}
Keywords: building construction; safety evaluation; indicator system; Hopfield neural network Abstract: In view of the current problems in the process of implementing safety management system in building construction in our country, one model was established for safety evaluation on building construction with taking expert scoring as network input, security class as the output based on Hopfield neural network. It obtained security class II for a certain construction company, and it was consistent with the construction company's actual situation. Research shows that Hopfield neural network has very strong memory and association function, and reflects the digital characteristics of sample data. It is simple, convenient, fair, accurate and suitable for safety evaluation on building construction.
\end{abstract}

\section{Introduction}

With the constant quickening of the urbanization process and post-disaster reconstruction of our country, the construction develops rapidly in recent years[1]. However, a large number of casualties happened which had brought the serious negative impact to the industry and society at the same time[2]. In order to improve the safety management level of construction industry in our country fundamentally, to strengthen to monitor and prevent these risk factors in the production and business operation activities of construction unit, China increases monitoring and punishment intensity to the safety management of construction enterprise constantly. The establishment of safety management system in modern construction has become an important index to evaluate comprehensive strength, safety civilized construction fee charging, and rating of construction enterprises. Therefore, the establishment of safety management system in modern construction has been received widespread attention increasingly.

\section{Construction safety management system present situation}

The construction safety management in our country started late on systematic development. The situation of safety management had been in a more extensive and scattered situation in quite a long period of time. With the further development of Chinese reform and opening-up policy, many fields, including construction, have been starting sweeping reforms since the end of 1980s[3]. With the promulgation of the relevant laws and regulations on construction safety management in the Safety Production Law, Building Law, Criminal Law and Civil Law, the responsibility system in the field of construction safety management is established and improved gradually. Especially, put forward the principle of comprehensive guidance that security is main, prevention first, governance comprehensive. The basic principle of construction safety management in our country was established formally. It marked that the establishment of safety management system of modern construction in our country was basically completed. It mainly includes the following aspects[4]:

(1) The level of government administration. China has established the legal system of safety production management with the Safety Production Law as the core on the level of government administration. The local administrative departments and industry management departments also introduced a large number of cooperative laws and regulations. The three aspects of civil, administration and Criminal Law constitute the legal system skeleton of safety production management in our country. The rights and responsibilities of the government, production units, regulators, employees and third parties social forces have been confirmed in the management of 
production safety. The management of safety production is given executive force of law from the coercive force of the state and administrative management. It not only changed the disordered situation of safety production management in our country, but also undefined relations of power, responsibilities and interests fundamentally.

(2) The level of industry standard. China has perfected the evaluation of safety production management and regulatory system of the three major dangerous industry production enterprises, such as mining, construction, dangerous goods in the production, transportation and storage. On the one hand, the mandatory provisions have been made to adapt with the industry which the enterprise belongs to, the scale of the size in the safe production management investment. At the same time, the clear certification system of safety production management is established in the industry. On the other hand, technical specification requirements have been proposed for dangerous operations and labor protection equipment of production and management process of construction enterprises, such as the Three Treasures (safety helmets, safety nets and safety belts), and operating specifications of special operation (tower crane, lifting, etc.). Above these play an important part in improving the industry standardization of construction enterprises.

(3) The level of employees. For safety production management of employees, the professional certification and training certification system of special assignments have been set up preliminarily in our country. On the one hand, establishing the professional certification and training management system of special talents of "safety engineers". On the other hand, setting up education and training system of safety production management, special assignments and on-duty-with-the-certificate mechanism of major hazards operation for the frontline staffs. It has a positive meaning to promote the quality of construction safety production and administration in our country.

\section{Discrete Hopfield network}

Discrete Hopfield neural network is a single layer feedback network with the input as two-value. The structure of discrete Hopfield neural network including $\mathrm{n}$ neurons was shown in figure 1.

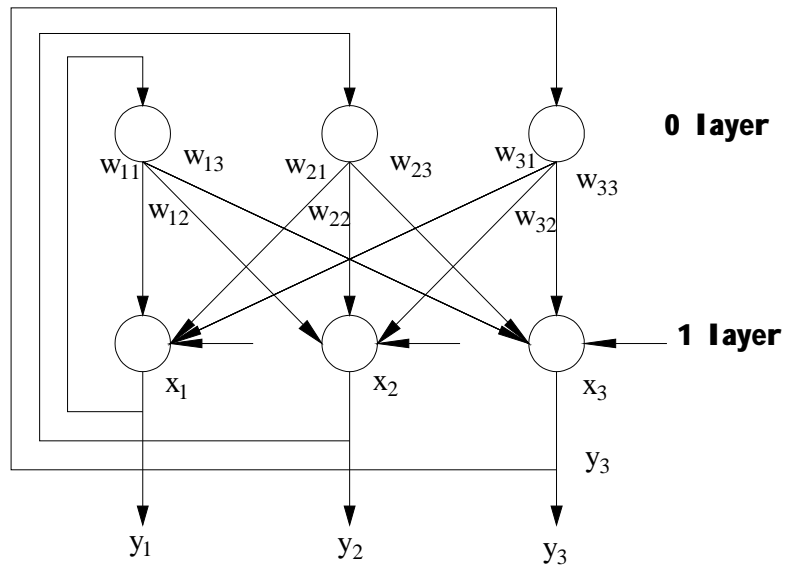

Fig.1 The structure of discrete Hopfield neural network

Neurons in the first layer sum up the product of the input information and the weight coefficient. The output information is generated by treatment of the nonlinear threshold function $f$. For an output layer with $n$ neurons network, its state at time $\mathrm{t}$ is a $n$-dimensional vector.

$$
Y(t)=\left[y_{1}(t), y_{2}(t), \ldots, y_{n}(t)\right]^{T}
$$

There are $2^{\text {n }}$ network states because $y_{i}(t)(i=1,2, \ldots, n)$ can be valued to 1 or -1 . As the state of node $\mathrm{j}$ of DHNN at time $\mathrm{t}$, the node at time $(\mathrm{t}+1)$ can be obtained as follow:

$$
y_{i}(t+1)=f\left[u_{j}(t)\right]=\left\{\begin{array}{l}
1, u_{j}(t) \geq 0 \\
-1, u_{j}(t)<0
\end{array}\right.
$$




$$
u_{j}(t)=\sum_{i=1}^{n} \omega_{i j} y_{i}(t)+x_{j}-\theta_{j}
$$

Hopfield adopts orthogonal method to modify weight and the overall adjustment algorithm is as follow:

Step 1: To input $\mathrm{N}$ input modes $t=\left\{t, t^{2}, \ldots, t^{N-1}, t^{N}\right\}$ and parameters $\tau, \mathrm{h}$;

Step 2: To calculate $A=\left\{t-t^{N}, t^{2}-t^{N}, \ldots, t^{N-1}-t^{N}\right\}$;

Step 3: To check $A$ into singular value decomposition $A=U S V^{T}$ and calculate the $\operatorname{rank} K=\operatorname{rank}(A)$ of $\mathrm{A}$;

Step 4: To calculate $T^{p}=\sum_{i=1}^{K} u^{i}\left(u^{i}\right)^{T}$ and $T^{m}=\sum_{i=K+1}^{N} u^{i}\left(u^{i}\right)^{T}$ from $U^{p}=\left\{U^{1}, U^{2}, \ldots, U^{k}\right\}$ and $u^{m}=\left\{u^{K+1}, u^{K+2}, \ldots, u^{N}\right\}$;

Step 5: To calculate $W^{t}=T^{p}-\tau \times T^{m}$ and $b^{t}=t^{N}-W^{t} \times t^{N}$;

Step 6: To calculate $W=\exp \left(h \times W^{t}\right)$;

Step 7: To calculate $\quad b=U \times\left[\begin{array}{ll}C_{1} \times I(K) & 0(K, N-K) \\ 0(N-K, K) & C_{2} \times I(N-K)\end{array}\right] \times U^{T} \times b^{\tau} \quad, \quad$ among them, $C_{1}=\exp (h)-1, C_{2}=-[\exp (-\tau \times h)-1] / \tau$.

The associative memory function of Hopfield neural network mainly gains through learning and association to realize the local minimum point of energy function until it reaches a stable state.

Learning process: according to the rules of Hebb to correct and adjust to the weight of sample data; Associative process: under the condition of keeping the weight constant, according to the dynamics learning rules to change the state of neurons and make the whole system convergence at a particular point, or cyclical iteration, or in a chaotic state.

The dynamic rule of Hopfield network is that if the network node is in the initial state $S(0)$, after the $t$ steps it will achieve the state $S(\mathrm{t}+1)$ by the following rules.

$$
S_{\mathrm{t}}(\mathrm{t}+1)=\operatorname{sgn}\left[\sum_{\mathrm{j}=1}^{\mathrm{n}} W_{\mathrm{ij}} S_{\mathrm{j}}(\mathrm{t})+\mathrm{I}_{\mathrm{i}}\right]
$$

Among them, sgn is sign function.

The associative memory learning algorithm is given, among them $\mathrm{I}=0$.

Step1: To set weights according to the Hebb rule.

$$
W_{\mathrm{ij}}=\left\{\begin{array}{l}
\sum_{\mathrm{m}=1}^{\mathrm{n}} x_{i}^{m} x_{j}^{m}, i \neq j, i, j=1,2, \ldots, n \\
0, i=j
\end{array}\right.
$$

Among them, $W_{\mathrm{ij}}$ is connecting weight from node $i$ to node $j ; x_{i}{ }^{m}$ represents the $i$ element of the samples sets $\mathrm{m}, \quad x i \in\{-1,+1\}$.

Step 2: To initialize the unknown samples

$$
S_{i}(0)=x_{i}, i=1,2, \ldots, n
$$

Among them, $S_{i}(t)$ is the output of node $i ; x_{i}$ is the $i$ element of the unknown sample.

Step3: To iterative calculate.

$$
S_{\mathrm{t}}(\mathrm{t}+1)=\operatorname{sgn}\left[\sum_{\mathrm{j}=1}^{\mathrm{n}} W_{\mathrm{ij}} S_{\mathrm{j}}(\mathrm{t})\right]
$$

Until the output states of the node not changed, the iteration is over.

Step 4: To return Step 2. 
The associative memory function of the Hopfield neural network gradually tends to a stable state after the above four steps of dynamic learning rules.

\section{Construction safety evaluation model}

\section{Evaluation indexes and evaluation standards}

Whether the selection of comprehensive safety evaluation indexes is appropriate or not will directly affect the accuracy and credibility of evaluation[5]. Therefore, establishing reasonable safety evaluation index system is the key to the comprehensive evaluation of construction safety. A scientific comprehensive evaluation index system of building construction safety has been established based on analytic hierarchy process, which combined with the expert opinion and the suggestion[6 7]. It was shown in table 1.

Table 1 Comprehensive evaluation index system of construction safety

\begin{tabular}{|c|c|c|}
\hline \multirow{17}{*}{$\begin{array}{l}\text { evaluation } \\
\text { index } \\
\text { system A }\end{array}$} & \multirow{3}{*}{$\begin{array}{l}\text { Human } \\
\text { factors } B_{1}\end{array}$} & safe cultural character of leadership and safety technology level $\mathrm{C}_{1}$ \\
\hline & & safe cultural character of management and safety technology level $\mathrm{C}_{2}$ \\
\hline & & safe cultural character of operation and safety technology level $\mathrm{C}_{3}$ \\
\hline & \multirow{3}{*}{$\begin{array}{c}\text { Construction } \\
\text { equipment } \\
\text { factors } \mathrm{B}_{2}\end{array}$} & safety controls for large equipment and machine of construction stevedoring $\mathrm{C}_{4}$ \\
\hline & & equipment reliability testing $\mathrm{C}_{5}$ \\
\hline & & equipment maintenance $\mathrm{C}_{6}$ \\
\hline & \multirow{8}{*}{$\begin{array}{l}\text { Management } \\
\text { factors } B_{3}\end{array}$} & safety management organization and post setting \\
\hline & & the execution of construction safety regulations and industry standard \\
\hline & & establishment and implementation of regulations on construction site \\
\hline & & safety publicity and education and training level $\mathrm{C}_{10}$ \\
\hline & & the security check $\mathrm{C}_{11}$ \\
\hline & & site protection and security measure $\mathrm{C}_{12}$ \\
\hline & & accident prevention and emergency treatment $\mathrm{C}_{13}$ \\
\hline & & safety investment $\mathrm{C}_{14}$ \\
\hline & \multirow{3}{*}{$\begin{array}{l}\text { Environment } \\
\text { factors } \mathrm{B}_{4}\end{array}$} & climate conditions $\mathrm{C}_{15}$ \\
\hline & & noise and dust on construction site $\mathrm{C}_{16}$ \\
\hline & & construction lighting $\mathrm{C}_{17}$ \\
\hline
\end{tabular}

Steps of network design

Design ideal evaluation index of safety grade

Set evaluation index valves in the safety evaluation standard of construction with $\mathrm{I}-\mathrm{V}$ levels of construction safety grade as the equilibrium points of discrete Hopfield neural network , $\mathrm{T}=$ [class_1 class_2 class_3 class_4 class_5]. It was shown in table 2 . 
Table 2 Equilibrium points of Hopfield neural network

\begin{tabular}{cccccc}
\hline Index & I & I & II & IV & V \\
\hline Grade & 95 & 85 & 75 & 65 & 55 \\
$\mathrm{C}_{1}$ & 95 & 85 & 75 & 65 & 55 \\
$\mathrm{C}_{2}$ & 95 & 85 & 75 & 65 & 55 \\
$\mathrm{C}_{3}$ & 95 & 85 & 75 & 65 & 55 \\
$\mathrm{C}_{4}$ & 95 & 85 & 75 & 65 & 55 \\
$\mathrm{C}_{5}$ & 95 & 85 & 75 & 65 & 55 \\
$\mathrm{C}_{6}$ & 95 & 85 & 75 & 65 & 55 \\
$\mathrm{C}_{7}$ & 95 & 85 & 75 & 65 & 55 \\
$\mathrm{C}_{8}$ & 95 & 85 & 75 & 65 & 55 \\
$\mathrm{C}_{9}$ & 95 & 85 & 75 & 65 & 55 \\
$\mathrm{C}_{10}$ & 95 & 85 & 75 & 65 & 55 \\
$\mathrm{C}_{11}$ & 95 & 85 & 75 & 65 & 55 \\
$\mathrm{C}_{12}$ & 95 & 85 & 75 & 65 & 55 \\
$\mathrm{C}_{13}$ & 95 & 85 & 75 & 65 & 55 \\
$\mathrm{C}_{14}$ & 95 & 85 & 75 & 65 & 55 \\
$\mathrm{C}_{15}$ & 95 & 85 & 75 & 65 & 55 \\
$\mathrm{C}_{16}$ & 95 & 85 & 75 & 65 & 55 \\
$\mathrm{C}_{17}$ & 95 &
\end{tabular}

Ideal evaluation index encoding of safety grade

Two cases in neurons status of discrete Hopfield neural network are 1 and -1 . - indicates neurons status to "1"; $\quad 0$ indicates neurons status to "-1". Get the five ideal evaluation index encodes of safety grade. It was shown in figure 2 .

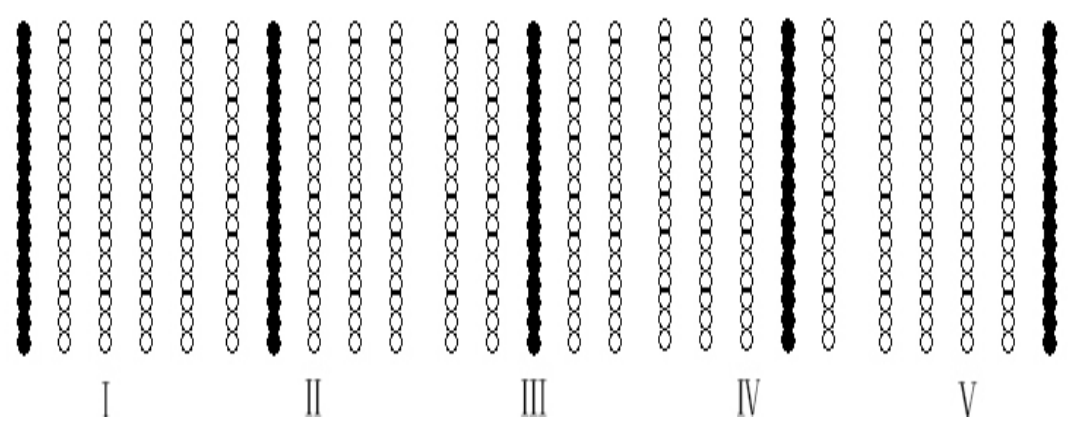

Fig.2 Five ideal evaluation index encoding

\section{Undetermined evaluation index encoding of safety grade}

The architectural safety indicators of a construction company are marked by experts as shown in table 3. The corresponding code has been received according to code rules. It was shown in figure 3 . 
Table 3 Evaluation index value of a construction company

\begin{tabular}{cccccc}
\hline Index & I & I & III & IV & V \\
\hline $\mathrm{C}_{1}$ & 1 & -1 & -1 & -1 & -1 \\
$\mathrm{C}_{2}$ & -1 & 1 & -1 & -1 & -1 \\
$\mathrm{C}_{3}$ & -1 & -1 & 1 & -1 & -1 \\
$\mathrm{C}_{4}$ & -1 & -1 & 1 & -1 & -1 \\
$\mathrm{C}_{5}$ & -1 & 1 & -1 & -1 & -1 \\
$\mathrm{C}_{6}$ & -1 & 1 & -1 & -1 & -1 \\
$\mathrm{C}_{7}$ & 1 & -1 & -1 & -1 & -1 \\
$\mathrm{C}_{8}$ & -1 & 1 & -1 & -1 & -1 \\
$\mathrm{C}_{9}$ & -1 & 1 & -1 & -1 & -1 \\
$\mathrm{C}_{10}$ & 1 & -1 & -1 & -1 & -1 \\
$\mathrm{C}_{11}$ & -1 & 1 & -1 & -1 & -1 \\
$\mathrm{C}_{12}$ & -1 & -1 & 1 & -1 & -1 \\
$\mathrm{C}_{13}$ & -1 & -1 & -1 & 1 & -1 \\
$\mathrm{C}_{14}$ & -1 & 1 & -1 & -1 & -1 \\
$\mathrm{C}_{15}$ & -1 & 1 & -1 & -1 & -1 \\
$\mathrm{C}_{16}$ & 1 & -1 & -1 & -1 & -1 \\
$\mathrm{C}_{17}$ & -1 & 1 & -1 & -1 & -1 \\
\hline
\end{tabular}

\section{Creation and simulation of network}

Establish net=newhop (T) by using the toolbox function of MATLAB neural network after the five ideal evaluation indexes and codes of safety grade designed. Set undetermined evaluation index code $A=\left\{\left[\operatorname{sim} \_1\right]\right\}$ as input to Hopfield neural network. $Y=\operatorname{sim}($. net, 25, 20 $\}\{,\{\}, A)$ can be attained after a number of studies.

\section{Result analysis}

The evaluation results of Hopfield neural network were shown in Figure 3.

The construction security level of this construction company is level II from the figure 3. It does conform to its actual situation. It shows that the designed Hopfield neural network can evaluate effectively. Then the security levels of construction can be evaluated objectively and fairly.

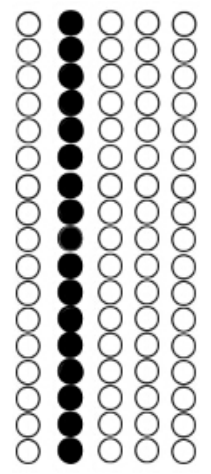

Fig.3 The evaluation results of Hopfield neural network

\section{Conclusion}

Safety evaluation model was established for building construction with taking expert scoring as network input, security class as the output based on Hopfield neural network. It obtained security class II for a certain construction company, and it was consistent with the construction company's actual situation. Research shows that Hopfield neural network has very strong memory and association function, and reflects the digital characteristics of sample data. It is simple, convenient, fair, accurate and suitable for safety evaluation on building construction. But the ability to evaluate is under the influence of the memory capacity and sample differences. Hopfield neural network will 
not obtain an accurate evaluation when it is fairly obvious that the advantages and disadvantages coexist in the construction. And it is unable to seek out the most close to balance point. It still needs further study.

\section{Acknowledgements}

This work is supported by Shandong wall materials innovation and building energy saving research and development project(No.2012QG007), Shandong science and technology project of department of housing and urban rural construction (No.2013RK031), Shandong science and technology project of department of housing and urban rural construction(2016).

\section{References}

[1] S.G. Huang, X. Yuan. Research and Application of Construction Safety Comprehensive Assessment System. Journal of Southwest University (Natural Science Edition),Vol.07,pp.130-135(2012).

[2] Q.F Li, M.X. Li, B.B. Xin. Study on Safety Evaluation in Building Construction According to WSR Methodology. He Nan Science, Vol.03,pp.309-312 (2010).

[3] Y.R. He, L. Wang, X. Li, C.Y. Song. Study on Comprehensive Safety Assessment of Construction Installation Sites based on BP Neural Network. China Safety Science Journal. Vol.12, pp.103-106 (2004).

[4] B. Liao. Application of fuzzy comprehensive evaluation method based on AHP in safety assessment of construction. Production safety science and technology of China.Vol.10,pp.172-176. (2013).

[5] X.N. Tang. The construction safety assessment system. Building material technology and application.Vol.03,pp.40-42(2008).

[6] B.J Jiang, Y.J. Sun, D.Y. He. Construction safety comprehensive evaluation index system of the building. Sichuan building, Vol. 01,pp.213-228 (2013).

[7] Y.M. Jin. The Safety Comprehensive Assessment System Study on Construction Field. Henan Science.Vol.14pp.173-176(2013). 